\title{
NUTRIÇÃO, SANIDADE, RENDIMENTO E QUALIDADE DE FRUTOS EM MACIEIRAS 'CATARINA' CONDUZIDAS SOB MANEJO INTEGRADO E ORGÂNICO'
}

\author{
JOÃO JOSÉ STÜPP², ELIETE DE FÁTIMA FERREIRA DA ROSA ${ }^{3}$ \\ CASSANDRO VIDAL TALAMINI DO AMARANTE ${ }^{4}$, ÁLVARO LUIZ MAFRA ${ }^{5}$, \\ CRISTIANO ANDRÉ STEFFENS ${ }^{3}$
}

\begin{abstract}
RESUMO - O objetivo deste estudo foi avaliar os efeitos dos sistemas de manejo integrado e orgânico sobre atributos de nutrição, sanidade, rendimento e qualidade de maçãs 'Catarina'. O estudo foi realizado em São Joaquim-SC, ao longo das safras de 2008/2009 e 2009/2010. O porta-enxerto era Marubakaido, com filtro de EM-9, e as macieiras conduzidas, em líder central. Os atributos do solo eram adequados ao desenvolvimento e produção das macieiras em ambos os sistemas. O sistema de manejo orgânico aumentou o teor de $\mathrm{Cu}$ nas folhas e $\mathrm{Ca}$ e $\mathrm{Cu}$ na casca e polpa dos frutos, a área de cor vermelha na epiderme dos frutos e a incidência de frutos com queimaduras por sol e com danos por mosca-das-frutas. O índice iodo-amido e o teor de sólidos solúveis foram superiores nos frutos do sistema orgânico. O manejo orgânico reduziu a área foliar média das plantas, e nos frutos reduziu as relações $\mathrm{K} / \mathrm{Ca}, \mathrm{Mg} / \mathrm{Ca}, \mathrm{N} / \mathrm{Ca}$ e $(\mathrm{K}+\mathrm{Mg}) / \mathrm{Ca}$ na casca e $\mathrm{Mg} / \mathrm{Ca}$ na polpa, a severidade de "russeting", o número de sementes e a acidez titulável. Não houve diferenças quanto aos demais atributos avaliados. A produção orgânica de maçãs é viável, desde que disponível tecnologia eficaz para o controle da mosca-das-frutas.
\end{abstract}

Termos para Indexação: Malus domestica, nutrição de plantas, composição mineral de maçãs, cobre em maçã orgânica, "bitter pit", mosca-das-frutas.

\section{NUTRITION, PESTS, YIELD AND FRUIT QUALITY OF 'CATARINA' APPLE TREES FROM ORCHARDS UNDER INTEGRATED AND ORGANIC PRODUCTION SYSTEMS}

\begin{abstract}
The objective of this study was to assess the effects of integrated and organic management systems on apples nutrition, incidence of pests, yield and fruit quality of 'Catarina' apple trees. The study was carried out in São Joaquim-SC, Brazil, in 2008/09 and 2009/10. Apple trees were grafted on Marubakaido rootstock (with EM-9 interstem), with slender spindle training. Soil attributes were adequate to the apple trees development and yield in both management systems. The organic management system increased the contents of $\mathrm{Cu}$ in the leaves and $\mathrm{Ca}$ and $\mathrm{Cu}$ in the fruit (skin and flesh tissues), increased the percentage of blush area in the fruit skin, and the incidence of fruits with sunburn and fruit fly damage. Fruits from the organic orchard had higher starch-iodine index and soluble solids content than those from the integrated orchard. In the organic orchard, the trees had lower mean leaf area, while fruits had lower $\mathrm{K} / \mathrm{Ca}, \mathrm{Mg} / \mathrm{Ca}, \mathrm{N} / \mathrm{Ca}$ and $(\mathrm{K}+\mathrm{Mg}) / \mathrm{Ca}$ ratios in the skin, and $\mathrm{Mg} / \mathrm{Ca}$ in the flesh, lower incidence of russeting, lower number of seeds and lower titratable acidity, compared to the integrated orchard. The two orchards did not show differences for the other attributes assessed. Organic apple production system is viable, since efficient technologies are adopted to prevent the attack of fruit fly.
\end{abstract}

Index terms: Malus domestica, plant nutrition, apples mineral composition, copper in organic apples, bitter pit, fruit fly.

\footnotetext{
'( Trabalho 003-13). Recebido em: 03-01-2013. Aceito para publicação em: 26-04-2013.

${ }^{2}$ Dr., Professor do Instituto Federal Catarinense (IFC), Câmpus Rio do Sul, Cx. Postal 441, CEP 89.160-000, Rio do Sul-SC, Brasil E-mail: a8jjs@cav.udesc.br

${ }^{3}$ Doutoranda em Manejo do Solo, Centro de Ciências Agroveterinárias (CAV), Universidade do Estado de Santa Catarina (UDESC). Av. Luiz de Camões, 2090, CEP 88520-000, Lages-SC, Brasil. E-mail: elietedarosa@ig.com.br

${ }^{4}$ Dr., Bolsista de Produtividade em Pesquisa do CNPq, Professor do Departo de Agronomia, CAV/UDESC. Av. Luiz de Camões, 2090, CEP 88520-000, Lages-SC, Brasil. E-mail: amarante@cav.udesc.br, steffens@cav.udesc.br

${ }^{5}$ Dr., Bolsista de Produtividade em Pesquisa do CNPq, Professor do Departo de Solos e Recursos Naturais, CAV/UDESC. Av. Luiz de Camões, 2090, CEP 88520-000, Lages-SC, Brasil. E-mail: a2alm@cav.udesc.br
} 


\section{INTRODUÇÃO}

O Brasil ocupa a $7^{\mathrm{a}}$ posição mundial em eficiência produtiva e tecnologias utilizadas no cultivo e processamento de maçãs, com uma área plantada de 38,2 mil ha e uma produção de 1,2 milhão de toneladas na safra de 2009/2010 (PETRI et al., 2011). Diversos sistemas de manejo na produção de maçãs são empregados e caracterizam-se por apresentarem substanciais diferenças quanto às tecnologias adotadas. Simultaneamente, frutos livres de resíduos de agroquímicos, saudáveis e com bom aspecto visual estão cada vez mais sendo buscados por produtores e consumidores mais esclarecidos e exigentes. A saúde e a sustentabilidade ambiental estão tornando-se parte da cultura das gerações atuais (HUBER, 2008).

$\mathrm{Na}$ produção de maçãs, três sistemas de manejo se destacam. O sistema convencional, que se caracteriza pelo emprego de todos os meios e recursos disponibilizados pela tecnologia na busca por maiores produções e produtividade, quase sempre com grande impacto sobre o meio ambiente. $\mathrm{O}$ sistema orgânico, que emprega métodos culturais, biológicos e mecânicos de baixo impacto sobre a diversidade biológica. E finalmente o sistema de produção integrada, que desde a sua introdução no Brasil, em 1996, emprega métodos e técnicas tanto do sistema convencional quanto do orgânico. Este último utiliza tecnologias de natureza preventiva e de melhoria das condições ambientais, porém admite o emprego de fertilizantes minerais e pesticidas sintéticos registrados para a cultura, menos impactantes sobre o ambiente, e com níveis de resíduos dentro de limites permitidos pelo sistema (PETRI et al., 2011). O manejo orgânico exclui o emprego de pesticidas e fertilizantes minerais. Neste manejo, prevalece o emprego de adubos verdes, estercos, compostos orgânicos, pós de rocha, caldas fungicidas à base de cobre e enxofre, inseticidas de origem vegetal, armadilhas e métodos de controle biológico (PECK et al., 2006). Assim, o sistema orgânico, que busca produção em base ecológica, pretende ser sustentável, socialmente justo, ecologicamente equilibrado, economicamente viável e culturalmente adaptado.

Tradicionalmente, o controle de insetos-praga e doenças é feito através da aplicação em cobertura de agroquímicos. Além de dispendiosos, estes produtos podem afetar inimigos naturais, reduzir a diversidade biológica e provocar desequilíbrio ambiental (SANTOS et al., 2007). A produção integrada de frutos busca o emprego racional de agroquímicos, o que pode não eliminar completamente os efeitos prejudiciais desses produtos sobre a diversidade biológica. Devido à preocupação com os riscos à saúde humana e com os efeitos ambientais indesejáveis, mais agricultores estão interessados na produção orgânica de maçãs (AMARANTE et al., 2008).

Diferentes autores têm comparado a qualidade das maçãs produzidas de forma convencional, integrada e orgânica, na colheita e após a armazenagem. Enquanto uns observaram substanciais diferenças entre maçãs de pomares manejados sob diferentes sistemas (RÓTH et al., 2007), há quem tem citado melhor qualidade das maçãs orgânicas em relação às provenientes de pomares integrados e convencionais (REGANOLD et al., 2001; WEIBEL et al., 2004; PECK et al., 2006). Outros ainda observaram mais semelhanças que diferenças entre frutos dos diferentes sistemas de manejo (ROUSSOS; GASPARATOS, 2009).

Ante o exposto, o objetivo deste estudo foi avaliar os efeitos dos sistemas de manejo integrado e orgânico sobre atributos de nutrição, sanidade, rendimento e qualidade de frutos em pomares de macieiras 'Catarina'.

\section{MATERIAL E MÉTODOS}

O estudo foi conduzido em São Joaquim-SC, (28 11' 52"S, 49 51' 40"O), a $1.170 \mathrm{~m}$ de altitude. O clima é mesotérmico úmido $(\mathrm{Cfb})$ de acordo com a classificação de Köppen, com maior precipitação durante os meses de agosto a março, atingindo média mensal equivalente a $191 \mathrm{~mm}$ durante as safras de 2008-2009 e 2009-2010. O solo é um Cambissolo Húmico, com atributos de $\mathrm{pH}$ e fertilidade adequados ao desenvolvimento e produção das macieiras, com teores de matéria orgânica equivalentes a $72 \mathrm{~g} \mathrm{~kg}^{-1}$ na camada de $0-20 \mathrm{~cm}$.

Dois pomares de maçãs com a cultivar Catarina foram estudados, um sob sistema de manejo integrado, implantado em 2002, e outro sob sistema de manejo orgânico, implantado em 2003. Os pomares eram próximos entre si (distância de $\sim 7.000 \mathrm{~m}$ ), em posição similar de topossequência, em relevo ondulado e em mesmas condições de solo. O porta-enxerto utilizado foi o Marubakaido, com filtro de M-9, e o sistema de condução das macieiras foi de líder central nos dois pomares. As áreas dos pomares eram constituídas originalmente de campos nativos, com predominância de espécies arbustivas e arbóreas, como o pinheiro- brasileiro (Araucaria angustifolia) e espécies de cobertura rasteira das famílias Asteraceae e Poaceae.

\section{Sistema integrado}

O solo foi corrigido com $30 \mathrm{Mg} \mathrm{ha}^{-1}$ de calcário dolomítico, $300 \mathrm{~kg} \mathrm{ha}^{-1}$ de superfosfato triplo, 120 $\mathrm{kg} \mathrm{ha}^{-1}$ de cloreto de potássio e $30 \mathrm{~kg} \mathrm{ha}^{-1}$ de bórax. 
Na formação do pomar, foram feitas três aplicações anuais de 30; 45 e $60 \mathrm{~g}$ de ureia planta $^{-1}$, no $1^{\circ}, 2^{\circ} \mathrm{e}$ $3^{\circ}$ anos, respectivamente. A adubação de reposição anual foi feita com $50 \mathrm{~kg} \mathrm{ha}^{-1}$ de $\mathrm{KCl}$ e $100 \mathrm{~kg} \mathrm{ha}^{-1}$ do adubo composto 20-10-20, na fase da brotação. Após a queda das pétalas, foram feitas aplicações quinzenais de $\mathrm{CaCl}_{2}(0,6 \%)$ para prevenção de distúrbios fisiológicos relacionados com a deficiência de $\mathrm{Ca}$. A quebra de dormência foi feita com óleo mineral $(3 \%)+$ cianamida hidrogenada $(0,3 \%)$ e o raleio de frutos, após o estabelecimento dos mesmos, com raleantes químicos, complementado manualmente. $\mathrm{O}$ controle da mosca-das-frutas foi feito com inseticidas específicos, recomendados para o manejo integrado. A cobertura vegetal do solo foi roçada duas vezes em cada ciclo cultural.

\section{Sistema orgânico}

O pomar sob manejo orgânico foi implantado em área cultivada, em anos anteriores à implantação das macieiras, com batata-semente manejada sob sistema convencional. O solo foi corrigido com 10 $\mathrm{Mg} \mathrm{ha}^{-1}$ de calcário, sendo 30\% dolomítico e $70 \%$ calcítico, $30 \mathrm{~kg} \mathrm{ha}^{-1}$ de bórax e $500 \mathrm{~kg} \mathrm{ha}^{-1}$ de fosforita, no quarto ano após a implantação. Para a formação das plantas, foi feita a aplicação de $1 \mathrm{~kg}$ planta $^{-1} \mathrm{ano}^{-1}$ de esterco de peru em cobertura e adubação verde nos três anos iniciais. A reposição de nutrientes foi feita com $2 \mathrm{~kg}_{\text {planta }}{ }^{-1}$ ano $^{-1}$ de esterco de aves, mais adubação verde. Não se fizeram aplicações adicionais de Ca foliar. A quebra de dormência foi natural, pelo somatório das horas de frio do período hibernal, e o raleio de frutos foi manual. As doenças foram controladas com calda sulfocálcica (24 aplicações safra $^{-1}$ ) e produtos à base de cobre (três aplicações em 2008/2009 e uma em 2010, em pós-colheita). Não se fez controle da mosca-das-frutas na safra de 2008/2009, e em 2009/2010 não houve ocorrência dessa praga. A cobertura verde do solo foi roçada duas vezes por ciclo cultural.

\section{Análises efetuadas}

Dez plantas foram selecionadas aleatoriamente em cada sistema de manejo (pomar), e avaliadas quanto à nutrição, sanidade (incidência de sarna e mosca-das-frutas), rendimento e qualidade dos frutos, durante as duas safras.

$\mathrm{O}$ solo junto às plantas selecionadas foi coletado e analisado em 2009 quanto aos atributos químicos (Tabela 1).

Foram contados todos os frutos com diâmetro ${ }^{3} 1,0 \mathrm{~cm}$, por cacho floral, 30 dias após a plena floração, antes do raleio. Na segunda quinzena de janeiro, em ambas as safras, procedeu-se à coleta de 100 folhas do terço médio dos lançamentos do ano, de cada planta marcada. Foi determinada a composição mineral foliar de $\mathrm{Ca}, \mathrm{Mg}, \mathrm{K}, \mathrm{N}$ e $\mathrm{Cu}$. $\mathrm{O} \mathrm{K}$ foi quantificado em fotômetro de chama, o $\mathrm{Ca}$ e $\mathrm{Mg}$, em espectrofotômetro de absorção atômica e o $\mathrm{N}$ foi determinado por destilação e titulação pelo método semimicro Kjehdahl, e seus teores, expressos em $\mathrm{g} \mathrm{kg}^{-1}$ de massa seca. $\mathrm{O} \mathrm{Cu}$ foi determinado após digestão nitro-perclórica em espectrofotômetro de absorção atômica, e os teores, expressos em $\mathrm{mg} \mathrm{kg}^{-1}$ de massa seca. Adicionalmente, determinaram-se o teor de clorofila foliar total (com um medidor de clorofila Minolta SPAD-502), a área foliar média $\left(\mathrm{cm}^{2}\right)$ e a área foliar específica $\left(\mathrm{cm}^{2} \mathrm{~g}^{-1}\right)$, em amostra de 20 folhas por planta, nos dois ciclos avaliados.

Na maturação comercial, todos os frutos de dois ramos selecionados por planta foram colhidos e avaliados quanto ao rendimento (número e massa de frutos por $\mathrm{cm}^{2}$ de secção transversal do ramo e massa média dos frutos). Vinte frutos por planta foram avaliados quanto à firmeza de polpa $(\mathrm{N})$, teor de sólidos solúveis (SS; ${ }^{\circ}$ Brix), índice de iodo-amido (1-5), acidez titulável (AT; \% de ácido málico), percentual de cor vermelha da epiderme, severidade de "russeting" ( $\mathrm{cm}^{2}$ por fruto), número de sementes por fruto e incidência (\%) de frutos com queimaduras pelo sol (nas duas safras), e danos de mosca-das-frutas (na safra de 2008/2009), segundo metodologia descrita por Amarante et al. (2008). Foram determinados os teores de $\mathrm{N}, \mathrm{K}, \mathrm{Ca}, \mathrm{Mg}$ e $\mathrm{Cu}$ nos frutos, nos tecidos da casca e da polpa, separadamente, segundo metodologia descrita para as folhas.

$\mathrm{O}$ experimento seguiu o delineamento inteiramente casualizado, com 10 repetições, cada repetição correspondendo a uma planta aleatoriamente marcada, em cada sistema de manejo. Os dados de cada cultivar foram submetidos à análise de variância $(p<0,05)$, com o uso do programa estatístico SAS.

\section{RESULTADOS E DISCUSSÃO}

Os atributos do solo eram adequados ao bom desenvolvimento e à produção das macieiras. $\mathrm{O} \mathrm{pH}$ do solo, próximo da neutralidade, indicava adequada correção da acidez na fase de implantação de ambos os pomares. Somente o teor de P no solo foi levemente menor que o recomendado para a cultura da macieira, segundo a Comissão de Química e Fertilidade do Solo (CQFS, 2004), em ambos os pomares (Tabela 1). O teor de $\mathrm{Mg}$ era menor no solo do pomar orgânico, em relação ao integrado, porém em ambos os pomares o teor de $\mathrm{Mg}$ encontrava-se dentro da faixa considerada adequada para a cultura da macieira, nas folhas e frutos (EPAGRI, 2006).

De acordo com a Epagri (2006), os teores 
foliares de $\mathrm{Ca}$ eram adequados à cultura, enquanto os teores de $\mathrm{K}, \mathrm{Mg}$ e $\mathrm{N}$ se encontravam um pouco acima dos níveis considerados suficientes, em ambos os sistemas de manejo (Tabela 2). Todavia, não foram observadas diferenças quanto aos teores de $\mathrm{Ca}, \mathrm{K}$, $\mathrm{Mg}$ e $\mathrm{N}$ em folhas, entre os dois sistemas, diferentemente do verificado por Amarante et al. (2008), que observaram teores de $\mathrm{Mg}$ maiores em folhas de macieiras 'Royal Gala' cultivadas sob manejo orgânico, comparativamente ao sistema integrado. Com relação ao $\mathrm{Cu}$, porém, o teor nas folhas das plantas sob manejo orgânico esteve significativamente acima da faixa de normalidade (EPAGRI, 2006), devido às aplicações de calda bordalesa na safra de 2008/2009 (Tabela 2).

Nos frutos, o teor de Ca foi maior no sistema orgânico, tanto na casca quanto na polpa (Tabela 2). A literatura internacional, de forma geral, considera que o teor de $\mathrm{Ca}$ adequado para preservar a qualidade e prevenir a ocorrência de distúrbios fisiológicos em maçãs, em pós-colheita, deve ser maior do que 40 $\mathrm{mg} \mathrm{kg}^{-1}$ de massa fresca (AMARANTE et al., 2012). No presente trabalho, teores de Ca menores que 40 $\mathrm{mg} \mathrm{kg}^{-1}$ de massa fresca foram observados na polpa dos frutos de ambos os pomares, o que os torna mais vulneráveis a distúrbios relacionados à nutrição (Tabela 2). Os baixos teores de Ca na polpa de maçãs 'Catarina', de ambos os sistemas de manejo, podem ser decorrentes do menor aporte de Ca durante a fase de multiplicação celular, que ocorre até cerca de 40 dias após a plena floração, e do eventual colapso precoce do xilema no fruto (MIQUELOTO, 2011). Essa autora constatou que a capacidade de transporte de Ca para os frutos, via xilema, difere entre cultivares, sendo essa capacidade menor em maçãs 'Catarina', quando comparadas com maçãs 'Fuji'.

Segundo Amarante et al. (2006), em maçãs 'Catarina', o aumento na severidade de desordens fisiológicas relacionadas à nutrição, particularmente o "bitter pit", é resultante de baixas concentrações de $\mathrm{Ca}$ nos tecidos da casca e da polpa, e dos elevados valores das relações $\mathrm{Mg} / \mathrm{Ca},(\mathrm{K}+\mathrm{Mg}) / \mathrm{Ca}$ e $(\mathrm{K}+\mathrm{Mg}+\mathrm{N}) / \mathrm{Ca}$ na casca. Todavia, segundo esses autores, elevados valores da relação $\mathrm{Mg} / \mathrm{Ca}$ na casca são os melhores indicativos de frutos com alta suscetibilidade ao "bitter pit" para essa cultivar.

Não foram observadas diferenças quanto aos teores de $\mathrm{K}, \mathrm{N}$ e $\mathrm{Mg}$ na casca e na polpa dos frutos, entre os dois sistemas de manejo (Tabela 2). Diferentemente dos resultados obtidos neste trabalho, Amarante et al. (2008) relataram teores maiores de $\mathrm{N}$ e $\mathrm{K}$ em folhas e frutos de macieiras produzidas sob manejo integrado, enquanto Roussos e Gasparatos (2009) citaram teores maiores de K e Mg na polpa de frutos orgânicos. Esses nutrientes exercem papel fundamental no equilíbrio nutricional e na qualidade dos frutos na colheita e armazenagem, sendo o K e o $\mathrm{N}$ os nutrientes mais extraídos do solo pela macieira (NAVA, 2009). Maçãs com teor de $\mathrm{N}$ inferior a 500 $\mathrm{mg} \mathrm{kg}^{-1}$ e com relação N/Ca menor do que 14 apresentam menores riscos de desenvolver "bitter pit" (AMARANTE et al., 2010). A alta relação N/Ca afeta negativamente a firmeza de polpa, porque o $\mathrm{N}$ induz ao aumento do tamanho dos frutos, diluindo a concentração de $\mathrm{Ca}$ e aumentando a suscetibilidade desses frutos para a expressão de distúrbios e doenças, ligados à deficiência desse nutriente, no pomar e em pós-colheita. Ademais, excesso de $\mathrm{N}$ afeta negativamente a cor vermelha da epiderme em maçãs (NAVA, 2009).

As relações $\mathrm{Mg} / \mathrm{Ca}, \mathrm{K} / \mathrm{Ca},(\mathrm{K}+\mathrm{Mg}) / \mathrm{Ca}$ e N/ $\mathrm{Ca}$ na casca foram maiores em frutos do pomar sob manejo integrado, devido ao menor teor de $\mathrm{Ca}$ na casca desses frutos (Tabela 2). Na polpa, apenas a relação $\mathrm{Mg} / \mathrm{Ca}$ apresentou diferença entre os sistemas de manejo, sendo igualmente maior nos frutos do sistema integrado.

Correlação negativa entre a relação $\mathrm{K} / \mathrm{Ca}$ e firmeza de polpa em maçãs foi observada por Dilmaghani et al. (2004). Segundo esses autores, a relação K/Ca na polpa $\leq 25$ significa riscos menores de redução da firmeza de polpa em maçãs. Casero et al. (2004) verificaram correlação positiva entre teores de Ca e firmeza de polpa, e correlação negativa entre teores de $\mathrm{Ca}$ e AT, e teor de SS. Neste trabalho, porém, a relação K/Ca verificada na polpa dos frutos, de ambos os sistemas de cultivo, foi maior que 25 (Tabela 3), valor que pode predispor os frutos a menor firmeza de polpa e a menor capacidade de conservação.

Quanto aos teores de $\mathrm{Cu}$ no solo $(0-20 \mathrm{~cm})$, foram observadas diferenças significativas entre sistemas de manejo, com maiores teores no pomar orgânico (Tabela 1). Tais valores são considerados normais, na faixa de até $15 \mathrm{mg} \mathrm{kg}^{-1}$, para os solos da região (EPAGRI, 2006). Em todos os tecidos analisados (casca e polpa de frutos e folhas), foram observados maiores teores de $\mathrm{Cu}$ nos pomares sob manejo orgânico (Tabela 2). Segundo a Epagri (2006), teores de $\mathrm{Cu}$ entre 5 e $30 \mathrm{mg} \mathrm{kg}^{-1}$ de massa seca nas folhas são considerados normais em macieiras. Todavia, teores de $\mathrm{Cu}$ maiores que $30 \mathrm{mg} \mathrm{kg}^{-1}$ foram verificados no tecido foliar das macieiras sob manejo orgânico.

Fungicidas à base de $\mathrm{Cu}$ são largamente empregados no controle preventivo de doenças, particularmente as fúngicas, especialmente em pomares sob sistema de manejo orgânico. Os teores de $\mathrm{Cu}$ acima da faixa de normalidade, encontrados 
no tecido foliar do pomar orgânico, são decorrentes das pulverizações com fungicidas cúpricos, como a calda bordalesa e bordasul. Entretanto, em espécies caducifólias (como é o caso da macieira), o lapso de tempo de permanência do $\mathrm{Cu}$ na planta é normalmente curto, e os riscos de fitotoxidez são diminuídos. Todavia, a contaminação do solo de pomares tratados continuamente com produtos cúpricos pode ocorrer pelo acúmulo gradativo desse elemento na camada mais superficial e na medida em que ocorre a decomposição e a mineralização dos resíduos culturais, sendo diretamente proporcional à quantidade do produto cúprico aplicado e ao lapso de tempo em que o mesmo vem sendo usado, devido ao seu efeito cumulativo no solo (LI et al., 2005).

O pomar orgânico recebeu 24 pulverizações de calda sulfocálcica por ciclo cultural para o controle das diferentes doenças das macieiras. De acordo com Palmer et al. (2003), maçãs produzidas organicamente têm maior probabilidade de serem afetadas por doenças diversas, especialmente as fúngicas, do que maçãs de pomares convencionais e integrados, frequentemente tratados com produtos de síntese química, destinados à prevenção dos danos causados por fungos. Macieiras tratadas com calda sulfocálcica podem sofrer fitotoxidez, causada pelo enxofre molhável presente em sua composição, com redução do tamanho das folhas e do rendimento de frutos (PALMER et al., 2003).

A frutificação, o número de frutos, o rendimento e a massa média dos frutos não foram influenciados pelo sistema de manejo, apesar de o número de sementes por fruto ter sido menor no sistema orgânico (Tabela 3). Igualmente, o teor de clorofila foliar não diferiu entre os sistemas de manejo. Entretanto, Amarante et al. (2008) observaram alteração no teor de clorofila foliar e na redução da área foliar média e da área foliar específica em 'Royal Gala' e 'Fuji', e consequente redução de rendimento em 'Fuji', supostamente decorrente do emprego de caldas sulfocálcica (à base de enxofre molhável) e bordalesa (sulfato de cobre), em pomares sob manejo orgânico. Também não houve diferença com relação à área foliar específica entre os sistemas de manejo (Tabela 3). Todavia, o sistema orgânico exibiu menor área foliar média, o que pode estar relacionado com a incidência de uma doença fúngica secundária (Marssonina sp.) e com os tratamentos das macieiras com calda sulfocálcica (PALMER et al., 2003).

Diferenças quanto à firmeza de polpa, em frutos provenientes de ambos os sistemas de manejo, também não foram observadas (Tabela 3). Frutos do pomar sob sistema integrado tiveram maior AT, e os do sistema orgânico, maiores valores de SS ( ${ }^{\circ}$ Brix) e índice de iodo-amido, e maior incidência de queimaduras causadas pelo sol (Tabela 3). Estes efeitos em frutos do sistema orgânico podem ser devidos à queda precoce de folhas, provocada por doenças fúngicas diversas, e à maior exposição dos frutos à radiação solar. De acordo com Felicetti e Schrader (2009), a queimadura pelo sol observada neste estudo é do tipo menos severo, e caracteriza-se por manchas de cor bronze-amarelada na superfície dos frutos, devido à foto-oxidação das células do tecido epidérmico, prejudicando a aparência dos frutos.

A maior exposição dos frutos à radiação no pomar orgânico aumentou a intensidade de cor vermelha da casca (Tabela 3). Santos et al. (2007) afirmaram que a macieira é uma espécie que exige alta densidade de fluxo radiante na fase de maturação, pois a luz solar promove a síntese de antocianinas, tornando os frutos mais vermelhos.

Maçãs com maior severidade de "russeting" (Tabela 3) foram encontradas no pomar sob sistema integrado, o que pode estar associado à presença de determinadas moléculas químicas presentes em certos pesticidas que podem induzir o desenvolvimento desse distúrbio.

Sob manejo orgânico, podem ocorrer danos aos frutos decorrentes de infestação da mosca-das-frutas (Anastrepha fraterculus, Wiedemann). Esses danos são normalmente frequentes e severos, quando não são adotadas medidas eficazes de controle. No pomar sob manejo integrado, não se observaram danos por mosca-das-frutas, devido aos tratamentos com pesticidas específicos. Todavia, no pomar sob manejo orgânico, os danos foram severos, com registro de $97,5 \%$ de frutos danificados na safra de 2008/2009 (Tabela 3). A mosca-das-frutas é a principal praga em fruteiras de clima temperado cultivadas no Sul do Brasil. O ensacamento de frutos é o método que apresenta resultados satisfatórios na proteção dos frutos contra os danos por mosca-das-frutas e mariposa-oriental (TEIXEIRA et al., 2011), porém, implica aumento significativo da mão de obra e dos custos de produção. Todavia, para o sistema de manejo orgânico, constitui-se no único método eficaz disponível.

A cultivar Catarina foi obtida por cruzamento em que se visou à introdução do gene ' $\mathrm{Vf}$ ' de resistência à sarna e, por essa razão, essa cultivar não teve registros para essa doença, em ambos os sistemas de manejo.

Mais semelhanças que diferenças foram observadas entre pomares com maçãs 'Catarina' cultivados sob os sistemas de manejo integrado e orgânico, quanto aos diversos atributos avaliados. A adoção de tecnologia eficaz, econômica e de fácil 
aplicação para o controle da mosca-das-frutas pode viabilizar a produção orgânica de maçãs e torná- -la competitiva em relação aos demais sistemas de manejo.

TABELA 1- Atributos químicos dos solos nas profundidades de $0-10 \mathrm{~cm}$ e $10-20 \mathrm{~cm}$, em pomares de macieiras da cultivar Catarina sob sistemas de manejo integrado e orgânico. Médias de 10 repetições de cada pomar.

\begin{tabular}{cccccc|cccc}
\hline \multirow{2}{*}{ Pomar } & $\mathrm{pH}$ & $\mathrm{pH}$ & $\mathrm{N}^{(2)}$ & $\mathrm{P}$ & $\mathrm{Cu}$ & $\mathrm{K}$ & $\mathrm{Ca}$ & $\mathrm{Mg}$ & $\mathrm{Al}$ \\
\cline { 3 - 10 } & água & $\mathrm{CaCl}_{2}\left(\mathrm{~g} \mathrm{~kg}^{-1}\right)$ & $\left(\mathrm{mg} \mathrm{kg}^{-1}\right)$ & & $\left(\mathrm{cmol}_{c} \mathrm{dm}^{-3}\right)^{(3)}$ & \\
\hline \multicolumn{10}{c}{$0-10 \mathrm{~cm}$} \\
Integrado & $6,5 \mathrm{~ns}^{(1)}$ & $6,0 \mathrm{~ns}$ & $6,3 \mathrm{~ns}$ & $8,7 \mathrm{~ns}$ & $10,5^{*}$ & $0,72 \mathrm{~ns}$ & $11,5 \mathrm{~ns}$ & $4,5^{*}$ & $0,4 \mathrm{~ns}$ \\
Orgânico & 6,6 & 6,0 & 5,4 & 9,9 & 12,3 & 0,59 & 10,8 & 3,6 & 0,4 \\
\hline & \multicolumn{7}{c}{$10-20 \mathrm{~cm}$} \\
Integrado & $6,0 \mathrm{~ns}$ & $5,6 \mathrm{~ns}$ & $5,3 \mathrm{~ns}$ & $6,2 \mathrm{~ns}$ & $10,3^{* *}$ & $0,48 \mathrm{~ns}$ & $7,7 \mathrm{~ns}$ & $3,7 * *$ & $0,7 \mathrm{~ns}$ \\
Orgânico & 6,3 & 5,7 & 4,6 & 5,2 & 12,6 & 0,38 & 8,4 & 2,7 & 0,5 \\
\hline
\end{tabular}

(1) Níveis de significância para diferenças entre pomares integrado e orgânico, para cada atributo, na mesma profundidade do solo (ns: não significativo. ${ }^{* *}$ : significativo aos níveis de probabilidade de 0,05 e 0,01 , respectivamente). ${ }^{(2)}$ Nitrogênio total. ${ }^{(3)}$ Valores trocáveis.

TABELA 2- Composição mineral de folhas ( $\mathrm{g} \mathrm{kg}^{-1}$ de massa seca) e frutos ( $\mathrm{mg} \mathrm{kg}^{-1}$ de massa fresca), e relações minerais na casca e polpa dos frutos, em pomares de macieiras da cultivar Catarina sob sistemas de manejo integrado e orgânico. Médias de 10 repetições de cada pomar, e duas safras (2008/2009 e 2009/2010).

\begin{tabular}{|c|c|c|c|c|}
\hline Atributo Mineral & Pomar Integrado & Pomar Orgânico & Significância ${ }^{(1)}$ & $\mathrm{CV}(\%)$ \\
\hline & \multicolumn{4}{|c|}{ Folha ( $\mathrm{g} \mathrm{kg}^{-1}$ de massa seca) } \\
\hline $\mathrm{Ca}$ & 12,3 & 11,8 & $\mathrm{~ns}$ & 13,2 \\
\hline $\mathrm{K}$ & 16,2 & 18,1 & ns & 13,1 \\
\hline $\mathrm{Mg}$ & 2,78 & 2,66 & ns & 20,7 \\
\hline $\mathrm{N}$ & 28,7 & 29,7 & ns & 12,2 \\
\hline$\frac{\mathrm{Cu}}{}$ & 3,0 & 96,3 & *** & 44,2 \\
\hline & \multicolumn{4}{|c|}{ Casca do fruto (mg kg-1 de massa fresca) } \\
\hline $\mathrm{Ca}$ & 108 & 144 & *** & 14,1 \\
\hline $\mathrm{K}$ & 1379 & 1333 & ns & 15,5 \\
\hline $\mathrm{Mg}$ & 205 & 204 & ns & 8,5 \\
\hline $\mathrm{N}$ & 761 & 693 & ns & 10,3 \\
\hline 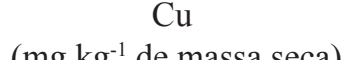 & 2,0 & 4,0 & $* * *$ & 30,9 \\
\hline $\mathrm{K} / \mathrm{Ca}$ & 13,2 & 9,2 & ** & 26,5 \\
\hline $\mathrm{Mg} / \mathrm{Ca}$ & 1,95 & 1,42 & $* * *$ & 17,0 \\
\hline $\mathrm{N} / \mathrm{Ca}$ & 7,2 & 4,8 & $* * *$ & 17,5 \\
\hline \multirow[t]{2}{*}{$(\mathrm{K}+\mathrm{Mg}) / \mathrm{Ca}$} & 15,1 & 10,7 & $* *$ & 24,6 \\
\hline & \multicolumn{4}{|c|}{ Polpa do fruto (mg kg-1 de massa fresca) } \\
\hline $\mathrm{Ca}$ & 26,4 & 32,9 & ** & 16,3 \\
\hline $\mathrm{K}$ & 1498 & 1591 & ns & 9,1 \\
\hline $\mathrm{Mg}$ & 35,4 & 34,3 & ns & 9,4 \\
\hline $\mathrm{N}$ & 270 & 290 & $\mathrm{~ns}$ & 14,6 \\
\hline $\begin{array}{c}\mathrm{Cu} \\
\left(\mathrm{mg} \mathrm{kg}^{-1} \text { de massa seca) }\right.\end{array}$ & 2,5 & 4,0 & $* * *$ & 19,3 \\
\hline $\mathrm{K} / \mathrm{Ca}$ & 58,1 & 49,3 & $\mathrm{~ns}$ & 18,9 \\
\hline $\mathrm{Mg} / \mathrm{Ca}$ & 1,37 & 1,07 & $* *$ & 18,1 \\
\hline $\mathrm{N} / \mathrm{Ca}$ & 10,5 & 8,9 & $\mathrm{~ns}$ & 17,4 \\
\hline$(\mathrm{K}+\mathrm{Mg}) / \mathrm{Ca}$ & 59,5 & 50,4 & ns & 18,9 \\
\hline
\end{tabular}

(1) ns: não significativo.** $\mathrm{e}^{* * *}$ : significativo aos níveis de probabilidade de 0,01 e 0,001 , respectivamente. 
TABELA 3- Atributos foliares, floração e frutificação efetiva, rendimento e qualidade e maturação dos frutos na colheita, em pomares de macieiras da cultivar Catarina sob sistemas de manejo integrado e orgânico. Os valores representam a média de 10 repetições de cada pomar, e duas safras (2008/2009 e 2009/2010), exceto para os dados de mosca-das-frutas, que correspondem a uma safra apenas $(2008 / 2009)$.

\begin{tabular}{|c|c|c|c|c|}
\hline Atributos & Pomar Integrado & Pomar Orgânico & Significância $^{(1)}$ & $\mathrm{CV}(\%)$ \\
\hline Área foliar média $\left(\mathrm{cm}^{2}\right)$ & 23,5 & 21,8 & $* *$ & 7,7 \\
\hline Área foliar específica $\left(\mathrm{cm}^{2} \mathrm{~g}^{-1}\right)$ & 94,4 & 94,4 & ns & 10,9 \\
\hline Massa seca de 100 folhas (g) & 5,3 & 4,7 & $*$ & 10,4 \\
\hline Teor de clorofila (leitura SPAD) & 50,9 & 49,7 & ns & 3,6 \\
\hline $\mathrm{N}^{\circ}$ de gemas $\mathrm{PCSR}^{(2)}$ & 7,2 & 5,8 & ns & 30,8 \\
\hline $\mathrm{N}^{o}$ de frutos PCSR & 1,5 & 1,2 & ns & 41,3 \\
\hline $\mathrm{N}^{0}$ de frutos $\mathrm{PCF}^{(3)}$ & 0,7 & 0,9 & ns & 46,8 \\
\hline Massa de frutos PCSR $(\mathrm{kg})$ & 0,28 & 0,21 & ns & 39,9 \\
\hline Massa média de frutos $(\mathrm{g})$ & 203,8 & 209,4 & ns & 11,8 \\
\hline Cor vermelha epiderme (\%) & 54,3 & 63,4 & $* * *$ & 8,1 \\
\hline "Russeting" $\left(\mathrm{cm}^{2}\right.$ fruto $\left.^{-1}\right)$ & 1,5 & 0,8 & $* * *$ & 31,9 \\
\hline Queimadura por sol (\%) & 7,0 & 20,0 & $* * *$ & 32,9 \\
\hline Danos por mosca-das-frutas (\%) & 0,00 & 97,5 & $* * *$ & 7,8 \\
\hline $\mathrm{N}^{\circ}$ de sementes/fruto & 5,1 & 4,7 & $*$ & 6,8 \\
\hline Índice de iodo-amido (1-5) & 2,3 & 3,1 & $* * *$ & 10,5 \\
\hline Firmeza de polpa (N) & 92,2 & 92,2 & ns & 3,8 \\
\hline Sólidos solúveis ( $\left.{ }^{\circ} \mathrm{Brix}\right)$ & 12,9 & 13,7 & $*$ & 5,0 \\
\hline $\begin{array}{l}\text { Acidez titulável } \\
\text { (\% de ácido málico) }\end{array}$ & 7,9 & 6,5 & $* * *$ & 9,4 \\
\hline
\end{tabular}

${ }^{(1)}$ ns: não significativo. *, ** e $\mathrm{e}^{* * *}$ : significativo aos níveis de probabilidade de $0,05,0,01 \mathrm{e} 0,001$, respectivamente. ${ }^{(2)} \mathrm{PCSR}$ : por $\mathrm{cm}^{2}$ de secção transversal de ramo; ${ }^{(3)}$ PCF: por cacho floral.

\section{CONCLUSÕES}

De modo geral, os sistemas de manejo integrado e orgânico pouco afetam os atributos avaliados em plantas e frutos de macieiras 'Catarina'. Ainda assim, o sistema orgânico aumenta os teores de $\mathrm{Ca}$ e $\mathrm{Cu}$ nas folhas e frutos, e o índice de iodo-amido e o teor de SS ( ${ }^{\circ}$ Brix) nos frutos. Igualmente, eleva a área de superfície vermelha na epiderme dos frutos e os danos por queimadura de sol e mosca-das-frutas. $\mathrm{O}$ teor de $\mathrm{Ca}$, menor nos frutos do pomar sob manejo integrado, eleva os valores das relações $\mathrm{K} / \mathrm{Ca}, \mathrm{Mg} /$ $\mathrm{Ca}, \mathrm{N} / \mathrm{Ca}$ e $(\mathrm{K}+\mathrm{Mg}) / \mathrm{Ca}$ na casca, e a relação $\mathrm{Mg} / \mathrm{Ca}$ na polpa desses frutos.

\section{REFERÊNCIAS}

AMARANTE, C.V.T.; ARGENTA, L.C.; BASSO, C.; SUZUKI, A. Composição mineral de maçãs 'Gala' e 'Fuji' produzidas no Sul do Brasil. Pesquisa Agropecuária Brasileira, Brasília, v.47, n.4, p.550560, 2012.

AMARANTE, C.V.T.; CHAVES, D.V.; ERNANI, P.R. Composição mineral e severidade de "bitter pit" em maçãs 'Catarina'. Revista Brasileira de Fruticultura, Jaboticabal, v.28, n.1, p.51-54, 2006.

AMARANTE, C.V.T.; STEFFENS, C.A.; ERNANI, P.R. Identificação pré-colheita do risco de ocorrência de "bitter pit" em maçãs 'Gala' por meio de infiltração com magnésio e análise dos teores de cálcio e nitrogênio nos frutos. Revista Brasileira de Fruticultura, Jaboticabal, v.32, n.1, p.27-34, 2010.

AMARANTE, C.V.T.; STEFFENS, C.A.; MAFRA, A.L.; ALBUQUERQUE, J.A. Yield and fruit quality of apple from conventional and organic production systems. Pesquisa Agropecuária Brasileira, Brasília, v.43, n.3, p.333-340, 2008. 
CASERO, T.; BENAVIDES, A.; PUY, J.; RECASENS, I. Relationships between leaf and fruit nutrients and fruit quality attributes in 'Golden Smoothee' apples using multivariate regression techniques. Journal of Plant Nutrition, Philadelphia, v.27, n.2, p.313-324, 2004.

CQFS - Comissão de Química e Fertilidade do Solo. Manual de Adubação e calagem para os Estados do Rio Grande do Sul e de Santa Catarina. 10.ed. Porto Alegre: Sociedade Brasileira de Ciência do Solo, 2004. 400p.

DILMAGHANI, M.R.; MALAKOUTI, M.J.; NEILSEN, G.H.; FALLAHI, E. Interactive effects of potassium and calcium on $\mathrm{K} / \mathrm{Ca}$ ratio and its consequences on apple fruit quality in calcareous soils of Iran. Journal of Plant Nutrition, Philadelphia, v.27, n.7, p.1.149-1.162, 2004.

EPAGRI - Empresa de Pesquisa Agropecuária e Extensão Rural de Santa Catarina. Manual da cultura da macieira. Florianópolis, 2006. 743p.

FELICETTI, D.A.; SCHRADER, L.E. Changes in pigment concentrations associated with sunburn browning of apple cultivars. II. Phenolics. Plant Science, Alexandria, v.176, n.1, p.84-89, 2009.

HUBER, J. Organic consumption-hype or future trend? Obstbau Weinbau, Jarhgang, v.45, n.10, p.313-314, 2008 .

LI, W.; ZHANG, M.; SHU, H. Distribution and fractionation of copper in soils of apple orchards. Environment Science \& Pollution Research, Berlin, v.12, n.3, p.168-172, 2005.

MIQUELOTO, A.; AMARANTE, C.V.T.; STEFFENS, C.A.; SANTOS, A. dos; MIQUELOTO, T.; SILVEIRA, J.P.G. Atributos fisiológicos, físico-químicos e minerais associados à ocorrência de "bitter pit" em maçãs. Pesquisa Agropecuária Brasileira, Brasília, v.46, n.7, p.689-696, 2011.

NAVA, G.; DECHEN, A.R. Long-term annual fertilization with nitrogen and potassium effect yield and mineral composition of 'Fuji' apple. Scientia Agricola, Piracicaba, v.66, n.3, p.377-385, 2009.
PALMER, J.W.; DAVIES, S.B.; SHAW, P.W.; WÜNSCHE, J.N. Growth and fruit quality of 'Braeburn' apple (Malus domestica) trees as influenced by fungicide programs suitable for organic production. New Zealand Journal of Crop and Horticultural Science, Wellington, v.31, n.2, p.169-177, 2003.

PECK, G.M.; ANDREWS, P.K.; REGANOLD, J.P.; FELLMAN, J.K. Apple orchard productivity and fruit quality under organic, conventional, and integrated management. HortScience, Alexandria, v.41, n.1, p.99-107, 2006.

PETRI, J.L.; LEITE, G.B.; COUTO, M.; FRANCESCATTO, P. Avanços na cultura da macieira no Brasil. Revista Brasileira de Fruticultura, Jaboticabal, v.33, p.48-56, 2011. Número especial.

REGANOLD, J.P.; GLOVER, J.D.; ANDREWS, P.K.; HINMAN, H.R. Sustainability of three apple production systems. Nature, Londres, v.410, n.1, p.926-930, 2001.

RÓTH, E.; BERNA, A.; BEULLENS, K.; YARRAMRAJU, S.; LAMMERTYNA, J.; SCHENK, A.; NICOLAÏ, B. Postharvest quality of integrated and organically produced apple fruit. Postharvest Biology and Technology, Amsterdam, v.45, n.1, p.11-19, 2007.

ROUSSOS, P.A.; GASPARATOS, D. Apple tree growth and overall fruit quality under organic and conventional orchard management. Scientia Horticulturae, Amsterdam, v.123, n.2, p.247-252, 2009.

SANTOS, P.J.; WAMSER, F.A.; DENARDI, F. Qualidade de frutos ensacados em diferentes genótipos de macieira. Ciência Rural, Santa Maria, v.37, n.6, p.1.614-1.620, 2007.

TEIXEIRA, R.; AMARANTE, C.V.T.; BOFF, M.I.C.; RIBEIRO, L.G. Controle de pragas e doenças, maturação e qualidade de maçãs 'Imperial Gala' submetidas ao ensacamento. Revista Brasileira de Fruticultura, Jaboticabal, v.33, n.2, p.394-401, 2011.

WEIBEL, F.; WIDMER, F.; HUSISTEIN, A. Comparison of production systems: integrated and organic apple production. Part III: inner quality - composition and sensory. Obst und Weinbau, Jarhgang, v.140, n.7, p.10-13, 2004. 